\title{
COVID-19 infection is related to differences in the use of personal protective equipment by orthopaedic specialist trainees caring for hip fracture patients during the second surge of COVID-19 in the North West of England
}

\author{
S. Mastan ${ }^{1}$ - R. A. Malik ${ }^{2,3} \cdot$ C. P. Charalambous ${ }^{1,4}$ on behalf of the COVIDHipFracture study group \\ Mustafa Abdulla · John Alonge · Ruth Chelva · Thomas Collins · Leanne Dupley · Azhar Din · John Ferns · \\ Ghazal Hodhody · Isabel Hughes · Aral Jamalfar · Chris Jump · Kenneth Koo · Alham Qureshi · Mobeen Qureshi • \\ Dhawal Patel · Neelam Patel · Adrian Pearce - Abubakar Rauf · Mohammed Ahmed Sajid · Samir Talha · Anna Walsh • \\ Abdulsalam Yasen · Nasri Zreik
}

Received: 26 January 2021 / Accepted: 11 May 2021 / Published online: 10 June 2021

(c) The Author(s), under exclusive licence to Springer-Verlag France SAS, part of Springer Nature 2021

\begin{abstract}
Introduction Personal protective equipment (PPE) may protect health-care workers from COVID-19 infection and limit nosocomial spread to vulnerable hip fracture patients.

Methods We performed a cross-sectional survey amongst orthopaedic trainees to explore PPE practice in 19 hospitals caring for hip fracture patients in the North West of England.

Results During the second wave of the pandemic, 14/19 (74\%) hospitals experienced an outbreak of COVID-19 amongst staff or patients on the orthopaedic wards. An FFP3 respirator mask was used by doctors in only 6/19 (32\%) hospitals when seeing patients with COVID-19 and a cough and in 5/19 (26\%) hospitals when seeing asymptomatic patients with COVID19. A COVID-19 outbreak was reported in 11/13 (85\%) orthopaedic units where staff wore fluid resistant surgical masks compared to $3 / 6$ (50\%) units using an FFP3 respirator mask (RR 1.69, 95\% CI 0.74-3.89) when caring for symptomatic patients with COVID-19. Similarly, a COVID-19 outbreak was reported in more orthopaedic units caring for asymptomatic patients with COVID-19 where staff wore fluid resistant surgical masks (12/14 (86\%)) as compared to an FFP3 respirator mask (2/5 (40\%)) (RR 2.14, 95\% CI 0.72-6.4).

Conclusion Urgent re-evaluation of PPE use is required to reduce nosocomial spread of COVID-19, amongst highly vulnerable patients with hip fracture.
\end{abstract}

Keywords COVID-19 $\cdot$ FFP3 $\cdot$ Surgical facemasks $\cdot$ Nosocomial covid

\section{Introduction}

COVID-19 is spread by direct or indirect contact with droplets released from the respiratory tract of an infected indi-

C. P. Charalambous

mr.charalambous@nhs.net

Blackpool Teaching Hospitals NHS Trust, Blackpool, UK

2 Department of Medicine, Weill Cornell Medicine-Qatar, Doha, Qatar

3 Institute of Cardiovascular Medicine, University of Manchester, Manchester, UK

4 School of Medicine, University of Central Lancashire, Preston, UK vidual during breathing, speaking, coughing or sneezing [1]. High rates of nosocomial COVID-19 infection have been reported in health-care workers (HCWs) and patients. We recently demonstrated very limited implementation of measures to prevent nosocomial spread during the second surge of the COVID-19 pandemic in orthopaedic units across NW England [2].

Between March and June 2020, HCW and their households accounted for one-sixth of the overall COVID-19 cases 
admitted to hospital in Scotland [3]. Indeed, it is estimated that $17.6 \%$ of all hospital admissions for COVID-19 infection may be nosocomial, with rates in the North West (NW) of England being as high as 25\% [4]. In the second surge of the pandemic, the NW of England witnessed a steep rise in the number of COVID-19 cases, with an estimated 1.8\% of the local population testing positive for SARS-CoV-2 in November 2020, the 2nd highest in the UK.

Patients admitted with hip fracture have a higher prevalence of COVID-19 and up to a sixfold increase in mortality compared to patients without COVID-19 [5]. Furthermore, $35 \%$ of all patients with hip fractures who died within 30 days of testing positive for COVID-19 caught the virus in hospital [6]. Personal protective equipment (PPE) such as masks, eye protection and long-sleeved gowns alongside general infection control measures are key to limiting the spread of infection. The provision of PPE may protect HCWs from contracting SARS-CoV-2 and also prevent transmission to other staff and patients.

Public Health England (PHE) has stipulated that contact with a COVID-19-positive patient requires minimal PPE (surgical mask, apron and gloves), with eye protection if bodily fluid secretion is anticipated, with full PPE (filtering face piece 3 (FFP3) respirator or equivalent, eye protection, long-sleeved gown and gloves) reserved for when undertaking an aerosol generating procedure (AGP). A systematic review identified 10 articles that classified coughing as aerosol generating, 5 as potentially aerosol generating and only 3 as non-aerosol generating [7]. However, PHE defined AGPs as medical procedures that release airborne particles from the respiratory tract, e.g. intubation, extubation, manual ventilation, bronchoscopy and induction of sputum using nebulisers, but excluded coughing.

The World Health Organization (WHO) recommends eye protection and a full-body gown when treating COVID19-positive patients even for non-AGPs [8]. Furthermore, the centre of disease control and prevention (CDC) recommends that the preferred PPE when dealing with confirmed or suspected COVID-19 patients should include an N95 respirator, eye protection and a full-body gown [9].

There is a paucity of evidence and considerable variation in guidance and implementation of PPE use when treating patients with COVID-19. We have assessed PPE practice in acute orthopaedic units in the NW of England caring for elderly patients with hip fracture who are particularly vulnerable to infection and mortality from COVID-19.

\section{Methods}

Orthopaedic specialist trainees in each hospital in the NW of England, identified through a North West Orthopaedic Research Collaborative, were invited to participate in the study and become a study collaborator. Where an orthopaedic trainee was not available, the orthopaedic doctor on call (ST1/ST2 or ST3 + level) was invited to participate. We defined a COVID-19 outbreak according to the PHE definition of 2 or more test-confirmed cases amongst individuals associated with illness in a non-residential setting, sharing onset dates within 14 days of each other, with the absence of another source of infection or an episode of direct exposure between cases. Participants were asked to capture the actual practice as opposed to the formal hospital policy, and report their awareness as to the occurrence of an outbreak. Participants were asked whether they wanted to be named as collaborators or whether they wished to remain anonymous. The survey was distributed via email or telephone between 23 November 2020 and 28 November 2020, and the questions are present in Tables 1 and 2. All data was analysed using Microsoft Excel. Relative risks (RR) and 95\% confidence intervals (CI) were calculated. Fisher's exact test was also used to compare rates of infection outbreaks between groups with statistical significance established at $P<0.05$ level.

\section{Results}

The survey included 19 of 23 acute orthopaedic trauma hospitals in the NW of England and had a 100\% completion rate (Tables 1,2). During the second wave of the pandemic 14/19 (74\%) hospitals experienced an outbreak of COVID19 amongst staff or patients on the orthopaedic wards, as reported by the respondents to the survey. A COVID-19 outbreak was reported in 11/13 (85\%) orthopaedic units where staff wore fluid resistant surgical masks compared to only 3/6 (50\%) units using an FFP3 respirator mask (RR 1.69, 95\% CI 0.74-3.89, Fisher's exact test $P=0.26$ ) when caring for symptomatic patients with COVID-19. A COVID-19 outbreak was reported in 12/14 (86\%) orthopaedic units where staff wore fluid resistant surgical masks compared to only 2/5 (40\%) units using an FFP3 respirator mask (RR 2.14, 95\% CI 0.72-6.4, Fisher's exact test $P=0.084$ ) when caring for asymptomatic patients with COVID-19. Post hoc analysis showed that in order to detect a statistically significant RR of the magnitude seen in this study, given our outbreak proportions and assuming a 2:1 ratio of sites using surgical masks compared to FFP3 respirators, a power of $80 \%$ and a significance level of 0.05 , there would be a need of including 65 sites (43 with surgical masks, 22 FFP3s) for when caring for symptomatic patients and 38 sites ( 25 surgical mask, 13 FFP3s) for when caring for non-symptomatic cases. 
Table 1 PPE use for symptomatic COVID-19-positive patients who are coughing, asymptomatic and COVID-19-negative patients

\begin{tabular}{|c|c|c|c|c|}
\hline Question & $\begin{array}{l}\text { COVID-19 symp- } \\
\text { tomatic coughing } \\
\text { patients } \\
N=19\end{array}$ & $\begin{array}{l}\text { COVID-19 asymptomatic patients } \\
N=19\end{array}$ & $\begin{array}{l}\text { COVID-19-negative } \\
\text { patients } N=19\end{array}$ & \\
\hline $\begin{array}{l}\text { What face mask does your trust recommend you } \\
\text { wear when seeing these patients for non-AGPs? }\end{array}$ & $\begin{array}{l}\text { Ear bound mask }-11 \\
\text { Head tie mask }-2 \\
\text { FFP3 respirator }-6\end{array}$ & $\begin{array}{l}\text { Ear bound mask-12 } \\
\text { Head tie mask-2 } \\
\text { FFP3 respirator-5 }\end{array}$ & Ear bound mask -19 & \\
\hline $\begin{array}{l}\text { Do you have access to the FFP3 respirator on the } \\
\text { ward if you want to use it? }\end{array}$ & $\begin{array}{l}\text { Yes-8 } \\
\text { No-11 }\end{array}$ & $\begin{array}{l}\text { Yes-8 } \\
\text { No-11 }\end{array}$ & $\begin{array}{l}\text { Yes-6 } \\
\text { No-13 }\end{array}$ & \\
\hline $\begin{array}{l}\text { Do you use a single-use apron or a full-body } \\
\text { gown when seeing these patients? }\end{array}$ & $\begin{array}{l}\text { Single-use apron-16 } \\
\text { Full-body gown-3 }\end{array}$ & $\begin{array}{l}\text { Single-use apron-17 } \\
\text { Full-body gown-2 }\end{array}$ & $\begin{array}{l}\text { Single-use apron-16 } \\
\text { Nothing-3 } \\
\text { Full-body gown-0 }\end{array}$ & \\
\hline $\begin{array}{l}\text { Does your trust recommend the use of head } \\
\text { coverings? }\end{array}$ & $\begin{array}{l}\text { Yes-1 } \\
\text { No-14 }\end{array}$ & $\begin{array}{l}\text { Yes-1 } \\
\text { No-18 }\end{array}$ & $\begin{array}{l}\text { Yes-0 } \\
\text { No-19 }\end{array}$ & \\
\hline $\begin{array}{l}\text { What eye protection does your trust recommend } \\
\text { when seeing these patients? }\end{array}$ & $\begin{array}{l}\text { Visor-13 } \\
\text { Goggles-1 } \\
\text { Nil-5 }\end{array}$ & $\begin{array}{l}\text { Visor-13 } \\
\text { Goggles-1 } \\
\text { Nil-5 }\end{array}$ & $\begin{array}{l}\text { Visor-3 } \\
\text { Goggles-1 } \\
\text { Nil-15 }\end{array}$ & \\
\hline $\begin{array}{l}\text { Does your trust practice include the use of } \\
\text { gloves? }\end{array}$ & $\begin{array}{l}\text { Yes-18 } \\
\text { No-1 }\end{array}$ & $\begin{array}{l}\text { Yes-18 } \\
\text { No-1 }\end{array}$ & $\begin{array}{l}\text { Yes-16 } \\
\text { No-3 }\end{array}$ & \\
\hline Do you change PPE between patients? & $\begin{array}{l}\text { Yes-17 } \\
\text { No-2 }\end{array}$ & $\begin{array}{l}\text { Yes-17 } \\
\text { No-2 }\end{array}$ & $\begin{array}{l}\text { Yes-16 } \\
\text { No-3 }\end{array}$ & \\
\hline $\begin{array}{l}\text { Does the aforementioned positive patient, wear a } \\
\text { mask, when tolerated, whilst in hospital? }\end{array}$ & & $\begin{array}{l}\text { Yes-17 } \\
\text { No-6 }\end{array}$ & $\begin{array}{l}\text { Yes-18 } \\
\text { No-5 }\end{array}$ & $\begin{array}{l}\text { Yes-9 } \\
\text { No- }-14\end{array}$ \\
\hline
\end{tabular}

Table 2 Confidence in hospital PPE policy by hospital doctors

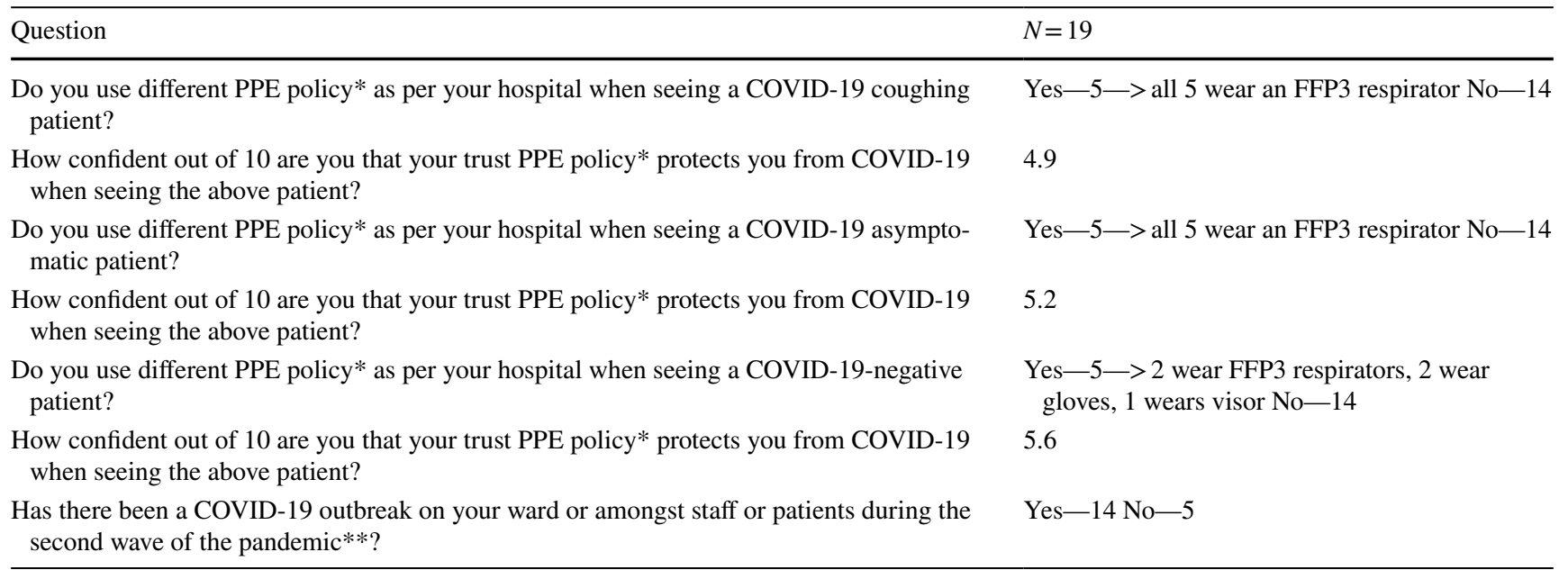

*By policy we meant observed trust practice and participants were made aware of this

**COVID-19 outbreak is as defined by the PHE definition of outbreak

\section{COVID-19-positive symptomatic patients with cough}

Of $19,14(74 \%)$ respondents reported they had looked after a COVID-19-positive patient with a hip fracture and cough. Of 19,14 (74\%) respondents reported that COVID19-positive patients wore a face mask. For doctors seeing patients with COVID-19 and a cough, 6/19 (32\%) hospitals recommended an FFP3 respirator and 3/19 (16\%) hospitals recommended a full-body protective gown, whilst 5/19 
(26\%) hospitals did not recommend eye protection. Of 19 , $8(42 \%)$ doctors had access to an FFP3 respirator when examining COVID-19-positive patients with a cough.

\section{COVID-19 asymptomatic patients}

Sixteen (84\%) respondents stated they had looked after an asymptomatic COVID-19 hip fracture patient. Of 19, 13 (68\%) hospitals required asymptomatic COVID-19 patients to wear a face mask. For doctors seeing asymptomatic patients with COVID-19, 5/19 (26\%) hospitals recommended an FFP3 respirator and 2/19 (11\%) required staff to use a full-body protective gown, whilst $5 / 19(26 \%)$ did not recommend eye protection. Of 19,8 (42\%) doctors had access to FFP3 respirators when examining asymptomatic patients with COVID-19.

\section{COVID-19-negative patients}

All 19 (100\%) hospitals required doctors to wear an ear bound surgical face mask when treating COVID-19-negative patients. The majority 13/19 (68\%) did not provide an FFP3 respirator on the ward, $3 / 19(16 \%)$ did not recommend the use of a surgical apron or gown, and of 19, 10 (53\%) inpatients did not wear a face mask.

\section{Doctors' confidence in PPE provided by the trust}

In 5/19 (26\%) hospitals, the orthopaedic trainee reported wearing an FFP3 face mask, which differed from their usual hospital practice when treating COVID-19-positive patients. The mean score for the doctors' confidence in their hospital's PPE practice was 4.9/10 when treating COVID19-positive patients who were coughing. Following this survey, we became aware that one hospital orthopaedic unit recommended the use of FFP3 respirator masks when seeing COVID-19-positive patients.

\section{Discussion}

Our data highlight a substantial variation in PPE use in hospitals in the NW of England amongst orthopaedic doctors managing hip fracture patients. Only $30 \%$ of hospitals recommended an FFP3 respirator mask, whilst the remaining $70 \%$ recommended a surgical mask when treating COVID19-positive patients with a cough. Furthermore, there was considerable variation in the use and availability of FFP3 respirator masks and eye protection.
A study from London showed that clinical staff had the highest rates of confirmed COVID-19 in hospitals, with doctors having the highest infection rates. The same study demonstrated that ITU staff had the lowest infection rate and that emergency department (ED) sickness rates dropped once ED staff started using PPE as recommended by PHE [10]. A study in Scotland showed that HCWs in patient facing roles were at a higher risk of COVID-19 compared to those in non-patient facing roles. The same study also showed that one-sixth of all COVID-19 hospitalised patients were HCWs or from their household [3]. Indeed, in the present study, $74 \%$ of the respondents stated that their orthopaedic unit had experienced a COVID-19 outbreak either amongst staff or patients during the second surge of this pandemic.

The current PHE guidance that recommends the use of a standard surgical mask is in line with a 2017 systematic review of trials in influenza, prior to the emergence of SARS-CoV-2 [11]. In a recent Cochrane review, the pooled results of randomised trials did not show a reduction in respiratory viral infection with the use of medical/surgical masks during seasonal influenza and there was also no clear difference between the use of medical/surgical masks compared with N95/P2 respirators in health-care workers to reduce respiratory viral infection [12]. However, in a study of seven COVID-19-positive participants who coughed over a petri dish, COVID-19 grew on 3/7 petri dishes of those wearing a fluid resistant surgical mask compared to none of those wearing a respirator mask [13]. There are currently no head-to-head trials assessing the effectiveness of standard surgical masks versus respirator masks with regards to infection with SARS-CoV-2. Ear bound surgical masks are considered to provide less protection than head bound masks due to a less tight seal. Indeed, in our study, a COVID-19 outbreak was reported in $86 \%$ of units where doctors wore surgical masks compared to only $40 \%$ of those wearing respirator masks. An ongoing randomised controlled trial in Alberta, Canada, is comparing the use of medical masks versus N95 respirators amongst nurses providing non-AGP care to patients with COVID-19 [14].

The WHO recommends the use of long-sleeved gowns, an apron and eye protection when treating COVID-19-positive patients, regardless of whether an AGP is being performed. Exposure simulation studies suggest that gowns may provide more protection, although the magnitude of this benefit has not yet been quantified [12]. In our survey, only one in five hospitals used long-sleeved gowns regularly when treating symptomatic patients with COVID-19, not undergoing AGPs.

Our survey also highlights a lack of confidence by orthopaedic specialist trainees in the national guidance to protect against workplace acquired COVID-19. Indeed, during the first surge of the pandemic, $54.7 \%$ of redeployed UK doctors did not feel safe when using PPE. The RCS has referred to 
a "postcode lottery" for PPE availability, with only 52\% of surgeons in Thames Valley and $34.7 \%$ of surgeons in the NW reporting adequate access [15].

We acknowledge limitations to our study. The findings were subjective as they were based on each doctor reporting their local practice in relation to PPE use, as opposed to hospital policy, and reported outbreaks were based on the respondent's awareness rather than an objective assessment of cases with COVID-19 in their unit. We were unable to recruit doctors from all 23 acute trauma hospitals in the NW to collaborate in the survey. Although substantial differences were seen in the absolute rates of infection outbreaks in comparing hospitals using surgical face mask versus FFP3 respirators, formal comparison did not reach statistical significance. However, this is likely due to the small number of hospitals included in this study, as evidenced by a post hoc analysis.

Nevertheless, our results demonstrate substantial variation in PPE use by orthopaedic specialist trainees caring for hip fracture patients in the NW of England during the 2nd surge of the COVID-19 pandemic [2]. This study calls for a significant improvement in the provision of PPE in NW England, given the potentially grave impact of COVID-19 infection in hip fracture patients.

\section{Declaration}

Conflict of interest The authors declare that they have no conflict of interests.

\section{References}

1. Ong SWX, Tan YK, Chia PY, Lee TH, Ng OT, Wong MSY, Marimuthu K (2020) Air, surface environmental, and personal protective equipment contamination by severe acute respiratory syndrome coronavirus 2 (SARS-CoV-2) from a symptomatic patient. JAMA 323(16):1610-1612

2. Mastan S, Cash T, Malik RA, Charalambous CP (2020) COVIDHipFracture study group. limited implementation of measures to reduce nosocomial spread of COVID-19 in hip fracture patients in the North West of England. J Hosp Infect 108:90-93

3. Shah AVS, Wood R, Gribben C, Caldwell D, Bishop J, Weir A et al (2019) Risk of hospital admission with coronavirus disease, in healthcare workers and their households: nationwide linkage cohort study. The BMJ 2020:371. https://doi.org/10.1136/bmj. $\mathrm{m} 3582$

4. Heneghan C, Howdon D, Oke J, Jefferson T. The Ongoing Problem of UK Hospital Acquired Infections. The Centre for
Evidence-Based Medicine. Accessed 17 December 2020 https:// www.cebm.net/covid-19/the-ongoing-problem-of-hospital-acqui red-infections-across-the-uk/

5. Clement ND, Ng N, Simpson CJ, Patton RFL, Hall AJ, Simpson AHRW, Duckworth AD (2020) The prevalence, mortality, and associated risk factors for developing COVID-19 in hip fracture patients: a systematic review and meta-analysis. Bone Joint Res 9(12):873-883

6. Narang A, Chan G, Aframian A, Ali Z, Carr A, Goodier H et al (2020) Thirty-day mortality following surgical management of hip fractures during the COVID-19 pandemic: findings from a prospective multi-centre UK study. Int Orthop. https://doi.org/10. 1007/s00264-020-04739-y

7. Jackson T, Deibert D, Wyatt G, Durand-Moreau Q, Adisesh A, Khunti K et al (2020) Classification of aerosol-generating procedures: a rapid systematic review. BMJ Open Resp Res. https://doi. org/10.1136/bmjresp-2020-000730

8. Rational use of personal protective equipment (PPE) for coronavirus disease (COVID-19). World Health Orgnisation. Accessed 17 December 2020 https://apps.who.int/iris/bitstream/handle/10665/ 331498/WHO-2019-nCoV-IPCPPE_use-2020.2-eng.pdf

9. Use Personal Protective Equipment (PPE) When Caring for Patients with Confirmed or Suspected COVID-19. CDC. Accessed 17 December 2020 https://www.cdc.gov/coronavirus/2019-ncov/ downloads/A_FS_HCP_COVID19_PPE.pdf

10. Zheng C, Hafezi-Bakhtiari N, Cooper V, Davidson H, Habibi M, Riley P et al (2020) Characteristics and transmission dynamics of COVID-19 in healthcare workers at a London teaching hospital. J Hosp Infect 106:325-329. https://doi.org/10.1016/j.jhin.2020.07. 025

11. Offeddu V, Yung CF, Low MSF et al (2017) Effectiveness of masks and respirators against respiratory infections in healthcare workers: a systematic review and meta-analysis. Clin Infect Dis 65(11):1934-1942

12. Jefferson T, Del Mar CB, Dooley L, Ferroni E, Al-Ansary LA, Bawazeer GA, van Driel ML, Jones MA, Thorning S, Beller EM, Clark J, Hoffmann TC, Glasziou PP, Conly JM (2020) Physical interventions to interrupt or reduce the spread of respiratory viruses. Cochrane Database Syst Rev 11:CD006207

13. Kim M-C, Bae S, Kim JY, Park SY, Lim JS, Sung M et al (2020) Effectiveness of surgical, KF94, and N95 respirator masks in blocking SARS-CoV-2: a controlled comparison in 7 patients. Infect Dis (Lond) 52:908-912. https://doi.org/10.1080/23744235. 2020.1810858

14. Cochrane Central Register of Controlled Trials (CENTRAL), Date Added to CENTRAL:31 March 2020 Issue Added to CENTRAL:2020 Issue 03

15. 'Postcode lottery' of PPE, survey of surgeons finds. Royal College of Surgeons of England. 2020 Accessed 17 December 2020

Publisher's Note Springer Nature remains neutral with regard to jurisdictional claims in published maps and institutional affiliations. 